Lack of fine-scale genetic structure and distant mating in natural populations of Fucus vesiculosus

Article in Marine Ecology Progress Series · February 2016 


\title{
Lack of fine-scale genetic structure and distant mating in natural populations of Fucus vesiculosus
}

\author{
Sara Teixeira, *, Gareth A. Pearson, Rui Candeias, Céline Madeira, \\ Myriam Valero, Ester A. Serrão
}

\begin{abstract}
Fine-scale spatial genetic structure (SGS) within populations reflects the dispersal behaviour of genes and individuals. Here we studied very small-scale SGS and mating patterns in the brown seaweed Fucus vesiculosus, a dioecious marine broadcast spawner with immediate settlement upon gamete release, which is predicted to strongly restrict gene flow. We estimated SGS, inbreeding and kinship for adults and recruits from habitats with contrasting exposures and patchiness (open coast and estuarine ecosystems) using microsatellite loci. Heterozygote deficiency was found for most adult populations but it was even higher for recruits, indicating inbreeding depression. At the fine spatial resolution of this study there was no spatial genetic structuring for 3 of the 5 populations studied across different habitats. Habitat could not explain the unrestricted gene flow in some populations. In the kinship analyses, we identified more putative mothers than fathers, suggesting that male gamete dispersal mediates gene flow at broader distances. However, the vast majority of the parents of the recruits could not be found among the adults sampled nearby, indicating unrestricted gene flow at these small scales. We propose 3 nonexclusive hypotheses for our findings: (1) unrestricted gene flow, (2) inbreeding depression eliminating most inbred individuals resulting from nearby related parents, (3) temporal Wahlund effects, mediated by a hypothetic genetic pool of a bank of microscopic forms persisting from previous generations.
\end{abstract}

KEY WORDS: Brown algae - External fertilizer - Spatial genetic structure - Inbreeding · Microsatellite markers $\cdot$ Spatial autocorrelation

Resale or republication not permitted without written consent of the publisher

\section{INTRODUCTION}

Dispersal is fundamental in the evolutionary dynamics of populations - rates, structure and scales of dispersal drive population replenishment and have profound implications for population persistence and evolution. High dispersal (or gene flow) tends to oppose the effects of local selection and thus limits adaptation. However, the amount of evidence for evolutionary divergence at small spatial scales for several species and in different geographic settings (e.g. Richardson \& Urban 2013) has increased, highlighting the importance of fine spatial-scale evolutionary processes.
At smaller spatial scales, dispersal influences processes, such as how species cope with competition, inbreeding depression and environmental changes (e.g. Ronce 2007). Restricted gene flow can lead to neighbouring individuals having higher genetic similarity, increasing the probability of inbred matings. Inbreeding can result in lower offspring fitness (i.e. inbreeding depression; reviewed by Delph 2004). Fitness can also decrease with distance when locally adapted genotypes exist (outbreeding depression; e.g. Waser \& Price 1994).

Both inbreeding and outbreeding depression can affect populations at different scales, resulting in an optimal outcrossing distance that maximizes fitness; 
even across relatively small distances (e.g. in a marine plant, Billingham et al. 2007). In marine algae, a few studies have addressed this issue. Inbreeding and outbreeding depression were negligible compared to heterosis as crossing success increased with distance between mates in an isomorphic haploiddiploid red alga (Richerd et al. 1993). In the heteromorphic haploid-diploid kelps, signatures of inbreeding depression have been found at small spatial scales in giant kelp (Raimondi et al. 2004, Johansson et al. 2013) but not in highly selfing ones (Barner et al. 2011). However, haploid life stages are expected to allow purging of deleterious mutations (e.g. Richerd et al. 1993, Engel et al. 2004, McKenzie \& Bellgrove 2006). Mechanisms to avoid and/or minimize inbreeding depression may also be mediated by the mating system, such as by selfing (e.g. Sletvold et al. 2013 and references therein).

The spatial genetic structure (SGS) within populations provides insight into the dispersal scales of genes and individuals at drift-dispersal equilibrium (Vekemans \& Hardy 2004). SGS is the decrease in mean pairwise genetic kinship with spatial distance, and the slope of the corresponding regression line is an indicator of SGS strength and gene flow limitation (Rousset 2000, Vekemans \& Hardy 2004). Therefore SGS can reflect the mating system if an SGS pattern arises by mating with closely related neighbours (or even selfing) due to reduced dispersal. This expected relationship remains a source of ongoing debate.

In marine habitats, few studies on small-scale SGS have been conducted. There is in particular a strong need to understand the influence of restricted propagule dispersal (i.e. in species without planktonic life stages) on small-scale SGS in marine environments, because it determines population evolution, persistence and recovery when facing perturbations. However, studies conducted to date have mainly focused on species with mixed mating systems that include clonality, such as seagrasses and sponges (Alberto et al. 2005, Calderón et al. 2007, Blanquer et al. 2009), or marine haploid-diploid algae, which are able to purge any deleterious mutations that arise during their haploid life cycle (Engel et al. 2004, Kusumo et al. 2006, Krueger-Hadfield et al. 2013, 2015). Very few studies have investigated SGS in strictly outcrossing species (Ledoux et al. 2010).

Our aim was to study small-scale SGS and mating patterns in the brown seaweed Fucus vesiculosus, a marine dioecious broadcast spawner (sensu Serrão \& Havenhand 2009) with no planktonic life stages, since the effect of habitat may be important in determining transportation and settlement that is depend- ent on substrate structure. This species can be found in a variety of habitats ranging from exposed intertidal rocky shores to highly sheltered tidal marshland areas, allowing comparisons of SGS across habitats. The genus Fucus has been a model system in the study of several ecological and evolutionary processes, particularly reproductive ecology (reviewed in Pearson \& Serrão 2006). On many shores, several species of this genus are found distributed according to a vertical gradient (Chapman 1995, Billard et al. 2010, Zardi et al. 2011), hybrid genotypes are rare and can be found only in the transition zones (Engel et al. 2005, Billard et al. 2010).

The reproductive biology of $F$. vesiculosus suggests this species will display SGS. The species releases gametes synchronously during calm periods (Serrão et al. 1996, Berndt et al. 2002, Monteiro et al. 2012), indicating very low potential for gamete dispersal. This gamete releasing strategy minimizes gamete dilution by currents and explains a female fertilization success close to $100 \%$ in all natural fucoid populations studied to date (Serrão et al. 1996, Ladah et al. 2003). Gametes are released in oogonia and antheridia that immediately sink to the bottom (settlement is immediate to spawning). Once gametes are in close contact, fertilization follows within minutes, and attachment of zygotes occurs a few hours later, depending on the temperature (Ladah et al. 2003, Coleman \& Brawley 2005a). Field studies on fucoid algae recorded that most eggs settle within $0.5 \mathrm{~m}$ of the source, although dispersal beyond 2 to $6 \mathrm{~m}$ may also occur, particularly in sperm (Serrão et al. 1997, Dudgeon et al. 2001). Dispersal could also be mediated via drifting reproductive thalli, until their senescence, as found for other brown algae (McKenzie \& Bellgrove 2008); however, since F. vesiculosus is dioecious, the gametes released by a drifting thallus need to encounter gametes of the opposite sex for fertilization to occur. Given these reproductive characteristics, we hypothesize a scenario of restricted gene flow and therefore a strong pattern of SGS, with matings occurring between genetically and spatially close males and females.

In previous population genetic studies of Fucus species, an important influence of mating system on the genetic diversity and structure of populations has been found, with higher genetic structure and lower genetic diversity associated with hermaphroditic $(F$. spiralis and F. guiryi) and dioecious species (F. serratus and F. vesiculosus) (Coyer et al. 2003, Coleman \& Brawley 2005a, Engel et al. 2005, Perrin et al. 2007). Given the low gamete dispersal, it is surprising that genetic studies on Fucus located on open shores indi- 
cated randomly distributed genotypes of $F$. vesiculosus sampled from an area ranging from 5 to $20 \mathrm{~m}^{2}$ (Engel et al. 2005) and at a scale of 1 to $100 \mathrm{~m}$ in F. serratus (Coyer et al. 2003). These results seem to indicate higher gamete or zygote dispersal than predicted for external fertilizers (Pearson \& Serrão 2006) and expected from ecological recruitment studies.

The aim of this study was to assess the genetic structure of $F$. vesiculosus at a microgeographic scale (as defined by Richardson et al. 2014) and to assess individual dispersal behaviour within populations. Our hypothesis is that there is spatial genetic structuring, and widespread heterozygote deficiency. Because F. vesiculosus occurs in habitats with contrasting exposures and patchiness that could potentially influence SGS and inbreeding, analyses were done in both natural open coast and estuarine populations.

\section{MATERIALS AND METHODS}

\section{Sample collection}

We sampled 5 natural populations of Fucus vesiculosus (Fig. 1) encompassing 2 types of ecosystems: open shores and estuaries. In open-shore ecosystems we sampled 2 populations in France (Roscoff $\left[48^{\circ}\right.$ $42^{\prime} 47.53^{\prime \prime} \mathrm{N}, 4^{\circ} 02^{\prime} 32.95^{\prime \prime} \mathrm{W}$ ] and Brest [48 $21^{\circ} 30.74^{\prime \prime} \mathrm{N}$, $\left.\left.4^{\circ} 32^{\prime} 31.79^{\prime \prime} \mathrm{W}\right]\right)$ and one population in northern Por-

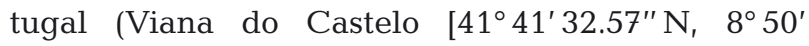
57.57" W]). In estuarine ecosystems we sampled 2 populations in Portugal, one in the north (Lima River

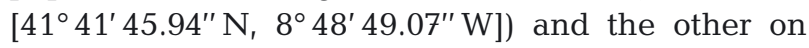
the central coast (Tagus River $\left[38^{\circ} 45^{\prime} 31.34^{\prime \prime} \mathrm{N}\right.$, $\left.\left.8^{\circ} 57^{\prime} 24.80^{\prime \prime} \mathrm{W}\right]\right)$.

To avoid confounding effects of unoccupied habitat in between areas of continuous distribution, we delimited sampling areas within natural continuous patches of $F$. vesiculosus, determined by the patchiness of its local distribution, therefore representing distinct shapes, areas and densities. Sampling areas were $1 \times 5 \mathrm{~m}$ in Tagus River, $3 \times 3.5 \mathrm{~m}$ in Roscoff (both populations with an average estimated density of 80 ind. $\mathrm{m}^{-2}$ ), $6 \times 2.5 \mathrm{~m}$ in Brest, $2.5 \times 2.5 \mathrm{~m}$ in the Lima River (both populations with an average estimated density of 50 ind. $\mathrm{m}^{-2}$ ) and $5 \times 15 \mathrm{~m}$ in Viana do Castelo (average estimated density of 250 ind. $\mathrm{m}^{-2}$ ). Within these sampling units we chose reproductive thalli (adults) randomly, without using a minimum set distance between sampled thalli (some were next to each other, $<1 \mathrm{~cm}$ ), we determined their gender, measured their length (from holdfast to the

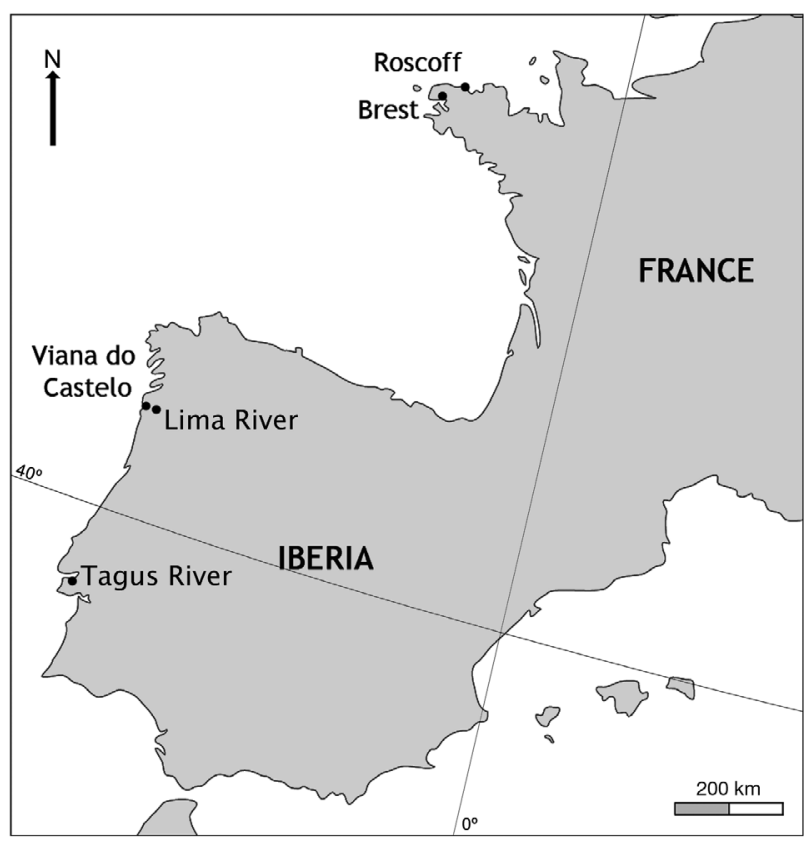

Fig. 1. Location of the Fucus vesiculosus populations sampled in this study

longest apical tip) and mapped them (for an example see Fig. S1 in the Supplement at www.int-res. com/articles/suppl/m544p131_supp.pdf). For each thallus, several vegetative tips were excised and dried in silica gel desiccant for DNA extraction. In $F$. vesiculosus, shoots from the same holdfast can belong to different individuals (Malm \& Kautsky 2004); however, in this study we genotyped 3 shoots from each thallus and used only the thalli that showed the same genotype for all sampled thalli, representing an individual sampling unit. Additionally, for one open-shore (Viana do Castelo) and one estuarine (Tagus River) population, recruits were measured, mapped and sampled for DNA extraction. We considered as recruits the thalli that were smaller than $5 \mathrm{~cm}$ total length and with no reproductive tissue. Although there is the possibility that a $5 \mathrm{~cm}$ thallus could be a new young shoot growing on an old holdfast instead of a new recruit, this is morphologically distinguishable; we chose thalli that had young, almost undetectable, holdfasts, and not small thalli growing from darker and larger holdfasts (the older ones).

\section{DNA extraction and microsatellite amplification}

DNA extraction was performed as in Coyer et al. (2009). For PCR reactions the extracted DNA was 
diluted 1:10. Nine microsatellite loci were amplified: F19, F3, F35, F57, F59, F26II, Fsp1, L20 and L78 (Engel et al. 2003, Wallace \& Klein 2004, Perrin et al. 2007, Coyer et al. 2009). Each $10 \mu$ reaction contained $10 \mathrm{ng}$ of genomic DNA, 1× Qiagen HotStart Taq buffer, $200 \mu \mathrm{M}$ of dNTPs, $0.3 \mu \mathrm{M}$ of each primer, different final concentrations of $\mathrm{MgCl}_{2}$ (Table S1 in the Supplement) and 0.5 U of HotStart Taq polymerase (Qiagen). PCR amplifications were conducted on a Perkin-Elmer Gene Amp System 7200 with the following program: $15 \mathrm{~min}$ at $95^{\circ} \mathrm{C}$; 30 cycles composed of $30 \mathrm{~s}$ at the annealing temperature (Table S1), $30 \mathrm{~s}$ elongation at $72^{\circ} \mathrm{C}$ and $30 \mathrm{~s}$ of denaturation at $95^{\circ} \mathrm{C}$, followed by a final 30 min elongation step at $72^{\circ} \mathrm{C}$. Fragments were separated on an ABI 3130 XL automatic sequencer (Applied Biosystems) with the internal size standard Rox 350 except for the locus F26II, where we used LIZ500 as an internal size standard. Alleles were scored using Peak Scanner version 1.0 (Applied Biosystems).

\section{Data analyses}

The mean number of alleles per locus (allelic diversity), the expected $\left(H_{\mathrm{E}}\right)$ and observed $\left(H_{\mathrm{O}}\right)$ proportion of heterozygotes, and the inbreeding coefficient $\left(F_{\text {IS }}\right)$ were estimated using GENETIX 4.05 (Belkhir et al. 1996). Significance levels were estimated using 1000 permutations. Linkage disequilibrium between all pairs of loci was tested according to the Black \& Krafsur (1985) procedure, with 1000 permutations. Allelic richness $(\hat{A})$ was estimated for each population separately, standardized to a minimum common size of 40 individuals per population using standArich (www.ccmar. ualg.pt/maree/software.php?soft=sarich). To determine the frequency of null alleles in the dataset we used the software ML-NULLFREQ (Kalinowski \& Taper 2006). We also used the software MICROCHECKER v.2.2.3 (van Oosterhout et al. 2004) which adjusts the number of homozygote genotypes in each size class to reflect the estimated frequency of null alleles and the 'real' number of homozygotes. Therefore, a new dataset of each locus was obtained by considering the adjusted genotypes. The effect of the possible presence of null alleles was evaluated comparing the results obtained using the 2 datasets. Correction for multiple testing was performed using the false discovery rate (FDR) approach (Benjamini \& Hochberg 1995) in QVALUE (Storey 2002).

\section{Spatial autocorrelation}

The genetic co-ancestry between pairs of individuals can be summarized over a range of distance intervals in terms of multilocus estimates of kinship $\left(\mathrm{F}_{i j}\right)$. We used the estimators of Loiselle et al. (1995) to calculate kinship coefficients between pairs of individuals using SPAGEDI (Hardy \& Vekemans 2002). Average kinship coefficients were estimated for a homogenised number of distance classes; 5, 10 and 20 distance classes were explored, but we show only the results for 5 classes because these contain more pairs per distance class, maximizing the power to detect departures from randomness. Correlograms were constructed by plotting the mean pairwise kinship coefficients as a function of the spatial distance class. Pairwise kinship coefficients were regressed on the logarithm of spatial distance for 2-dimensional populations to estimate the regression slope $\left(b_{\mathrm{F}}\right)$. For each population, spatial locations were randomly permuted among individuals 10000 times to test if the observed mean kinship values were different from those expected under a random distribution of genotypes. Gene dispersal parameters, Nb Wright's 'neighbourhood size' (Wright 1943), commonly perceived as the number of individuals that form a panmictic sub-population, and $\sigma^{2}$, which represents the mean-squared parent-offspring distance, were calculated by an iterative procedure. To calculate the dispersal parameters, the effective density $(D)$ must be estimated. This was calculated as the product of the census density (determined in the field for each population) and the $N_{\mathrm{e}} / N$ ratio (ratio of effective over census population sizes; Vekemans \& Hardy 2004). The dispersal parameters are only meaningful when an SGS pattern is present, as they are calculated based on the regression slope between kinship and geographical distance (Vekemans \& Hardy 2004). All these analyses were performed with SPAGEDI (Hardy \& Vekemans 2002). We further calculated the Sp statistic (Vekemans \& Hardy 2004) to quantify

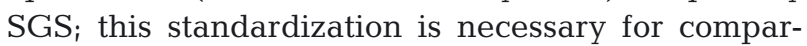
isons between studies and/or species, since the parameters mentioned above are to some extent dependent on the sampling scale used.

We further investigated whether different patterns could arise if we considered populations subdivided in cohorts. Therefore, we separately analyzed individuals of different sizes/length. Assuming classes that include thalli with $20 \mathrm{~cm}$ differences, starting at $20 \mathrm{~cm}$, we defined 4 size classes; Class 1: 20 to $40 \mathrm{~cm}$, Class 2: 41 to $60 \mathrm{~cm}$, Class 3: 61 to $80 \mathrm{~cm}$ and Class 4: 81 to $101 \mathrm{~cm}$. Only the Viana do Castelo population 
had thalli of all 4 size classes. In the Brest population, all thalli belonged to one size class (Class 2), and the remaining populations only had thalli belonging to Class 1. Finally, to assess if there was a spatial autocorrelation of sexual phenotypes, we analysed male and female thalli separately in all populations.

\section{Kinship structure}

To further analyse the relationship between thalli and to infer the possible origin of the parents and offspring, we used the maximum likelihood approach implemented in COLONY v.2.0 (Wang 2004, Wang \& Santure 2009, Jones \& Wang 2010), which assigns parentage and sibling- (sib)-ship from individual multilocus genotypes. Four categories of relationships are considered: unrelated, half-sibling, fullsibling and parent-offspring. The method uses a group-likelihood ratio to partition individuals into full- and half-sib families accounting for genotyping errors. Because age could not be estimated based on individual length, in this analysis only sampled recruits were used as offspring (sampled in Viana do Castelo and Tagus River), while their respective adult populations, comprised of thalli longer than $20 \mathrm{~cm}$ in length and with reproductive receptacles (explained above), were used as candidate male and female parents. The rate of errors used was according to the null allele frequencies calculated for each locus. We assumed polygamous mating systems for both males and females and used the full-likelihood method. The analysis was run 4 times and only relationships with a probability higher than 0.9 were considered.

\section{RESULTS}

\section{Genetic diversity}

Multilocus genotypes were obtained for 504 reproductive thalli from 5 sampled locations (Roscoff: 156, Brest: 50, Viana do Castelo: 212, Lima River: 44, Tagus River: 42) and 82 recruits from Viana do Castelo (45) and Tagus River (37). The analysis of the populations of reproductive thalli (adults) revealed high intra-population variability; the average number of alleles per population varied from north to south, with a maximum of 12.1 in Roscoff to a minimum of 4.9 in Tagus River (Table 1). The 9 loci used were highly variable, with mean number of alleles per locus ranging from 12 (F3) to 48 (F26II). However, the Tagus River population had very low amplification success for locus F26II, possibly due to mutation at primer binding sites. Also, at locus F57 all Tagus River thalli amplified were monomorphic. We therefore re-analyzed all populations with the remaining 7 loci.

For the 7 microsatellites, the number of alleles per locus varied from 12 to 22 (F3 and L20, respectively). Gene diversity (unbiased expected heterozygosity, $H_{\mathrm{E}}$ ) ranged from 0.72 (Roscoff) to 0.57 (Tagus River). Both allelic richness and gene diversity showed a northsouth decreasing trend, with higher genetic diversity in the 2 French populations, decreasing towards the south, with the most southern population (Tagus River) having the lowest genetic diversity of all.

\section{Inbreeding}

Estimations of $F_{\text {IS }}$ indicated highly significant heterozygote deficits for all populations, except Tagus River, after multiple test corrections (Table 1). In contrast with the reproductive adults of Viana do Castelo and the Tagus River, the genetic diversity of the recruits from these 2 populations revealed highly significant heterozygote deficit using the 7 microsatellites (Table 2). The possible presence of null alleles was detected for most markers used, with null allele frequencies ranging from 0.09 to 0.39 (Table S2 in the Supplement at www.int-res.com/articles/suppl/m544 p131_supp.pdf). Estimations of $F_{\text {IS }}$ using the 'corrected' dataset taking into consideration null allele frequencies, revealed lower $F_{\text {IS }}$ values but did not alter the results provided by the original dataset. 
Table 2. Genetic diversity of the recruits of the 2 populations of Fucus vesiculosus from Portugal. See Table 1 for description of variables. Bold numbers indicate significant values $(\mathrm{p}<0.05)$

\begin{tabular}{|lccccccc|}
\hline Population & Plot size & $N$ & $A$ & $H_{\mathrm{E}}$ & $H_{\mathrm{O}}$ & $F_{\mathrm{IS}}$ & $F_{\mathrm{IS}} \mathrm{C}$ \\
\hline Viana do Castelo & $5 \times 5 \mathrm{~m}$ & 45 & 6.1 & 0.66 & 0.57 & $\mathbf{0 . 1 3}$ & $\mathbf{0 . 1 0}$ \\
Tagus River & $1 \times 1 \mathrm{~m}$ & 37 & 4.4 & 0.56 & 0.29 & $\mathbf{0 . 4 9}$ & $\mathbf{0 . 2 5}$ \\
\hline
\end{tabular}

River -0.02 ( $\mathrm{p}<0.05)$, both in northern Portugal. The steeper regression slope for Lima River in relation to Viana do Castelo resulted in smaller $\mathrm{Nb}$ estimates and a stronger $\mathrm{Sp}$ statistic at this estuary population (Table 3 ). The $S p$ value found for Lima River is within the mean range found for outcrossing land plants (0.0126; Vekemans \& Hardy 2004).

The analysis per cohort was only possible for

\section{Spatial autocorrelation}

SGS at the thalli level did not reveal a pattern consistent with isolation by distance (IBD) within most populations, as in general the kinship coefficients did not decrease significantly with distance (Fig. 2). The regression slopes between genetic and geographic distances were significant for 2 of the 5 populations studied, Viana do Castelo -0.003 ( $\mathrm{p}<0.01)$ and Lima
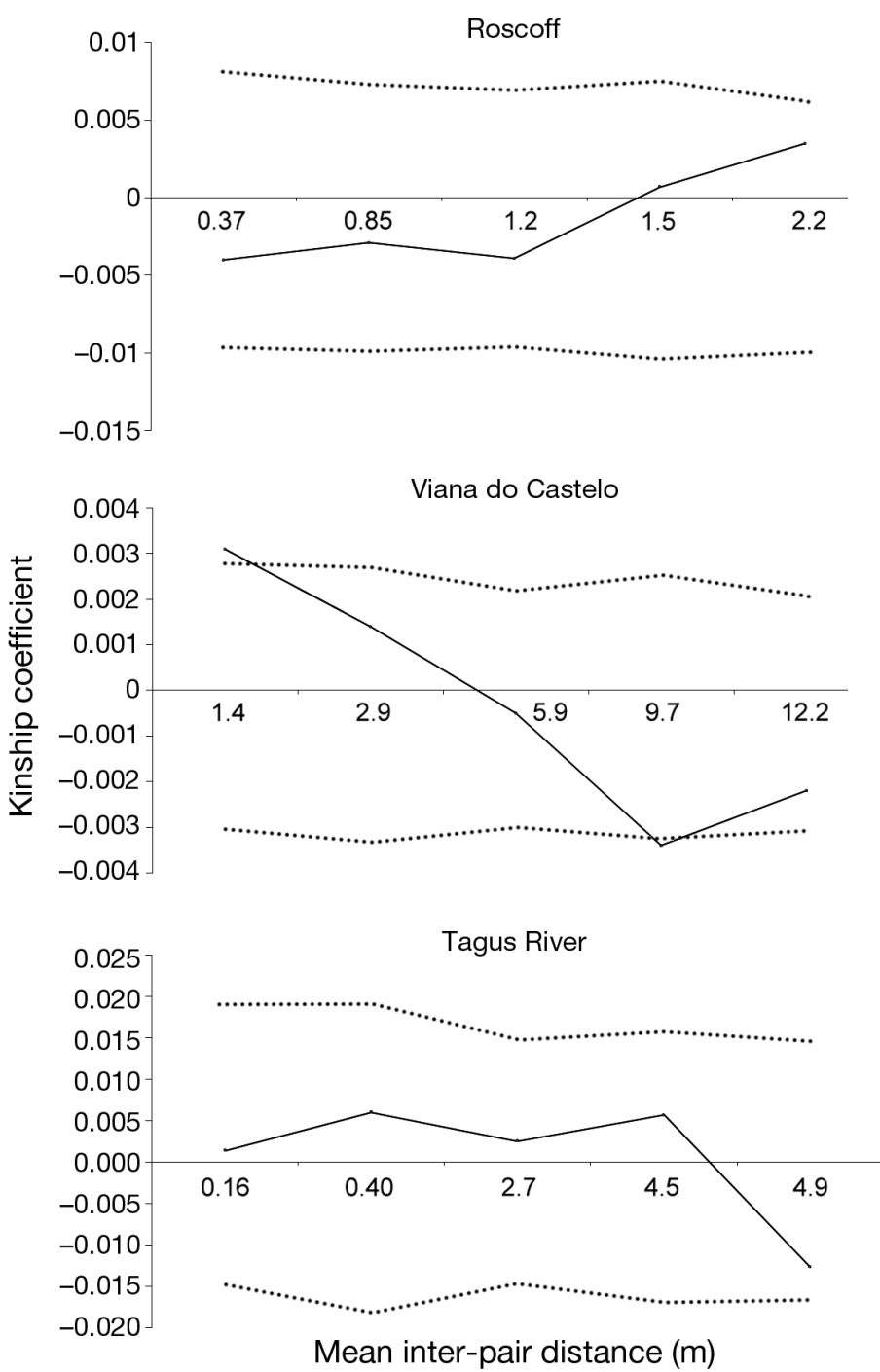
Viana do Castelo, because it had the 4 size classes. SGS was only found for thalli from Class 2 (41 to $60 \mathrm{~cm}$ length), with a significant regression slope $(-0.05, \mathrm{p}<$ 0.01). In all other classes, no relation was found between kinship and spatial distance (Fig. S2 in the Supplement). For the sexual phenotype, we found SGS to be significant for female thalli in the Viana do Castelo $\left(b_{\mathrm{F}}=-0.005, \mathrm{p}<0.05\right)$ population and for male thalli in Lima River ( $b_{\mathrm{F}}=-0.07, \mathrm{p}<0.05$; data not shown).
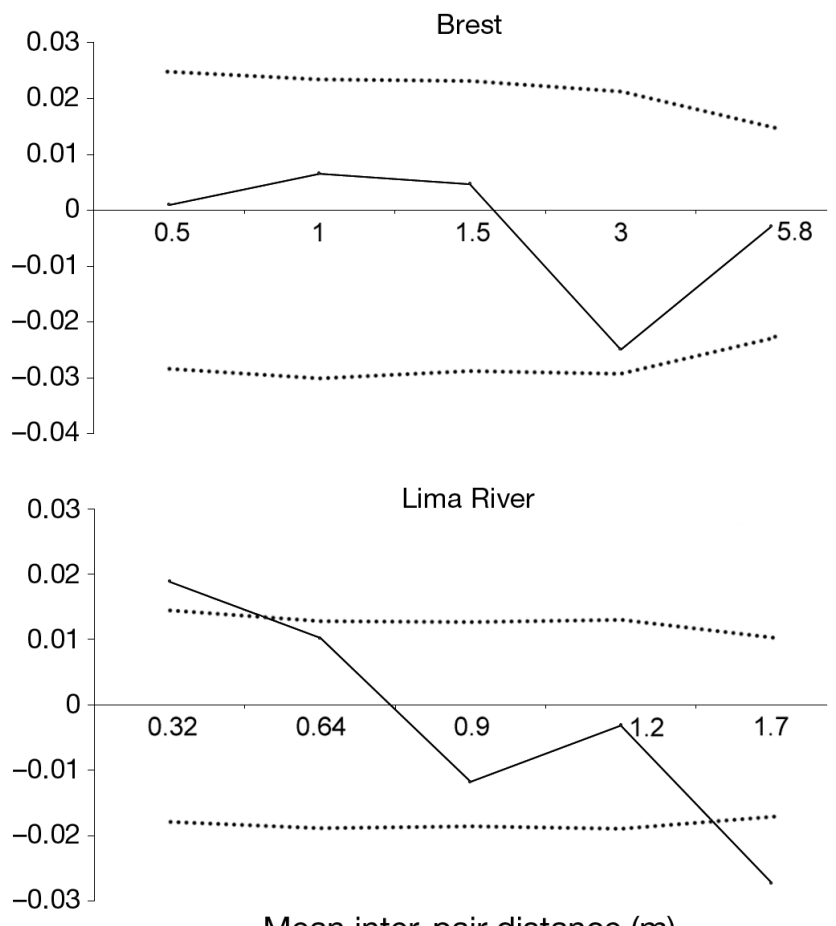

Mean inter-pair distance (m)
Fig. 2. Spatial autocorrelation graphs depicting the relationship between pairwise kinship coefficients and geographical distance between individuals of 5 populations of Fucus vesiculosus. Dotted lines indicate $95 \% \mathrm{CI}_{i}$ due to the different sizes of the sampled sites, the scale of the $x$-axis differs between graphs 
Table 3. Summary of kinship autocorrelation in the 5 Fucus vesiculosus populations studied. $F(1)$ : mean kinship values found for the shortest distance inter$\mathrm{val}_{;} b_{\mathrm{F}}$ : slope of the regression of mean kinship with the logarithm of spatial distance, $S p$ : $S p$ statistic; $D$ : estimated density of individuals in each population, $N b$ : estimated neighbourhood size, $\sigma$ : half the mean square parentoffspring distance. Significant values of $F(1)$ and $b_{\mathrm{F}}$ are shown in bold $(\mathrm{p}<0.05)$. na: not applicable

\begin{tabular}{|llccccccc|}
\hline Population & Habitat & $F(1)$ & $b_{\mathrm{F}}$ & $S p$ & $D$ & $N b$ & $\sigma$ \\
\hline Roscoff & Open shore & -0.004 & 0.0017 & na & 5 & na & na \\
Brest & Open shore & 0.001 & -0.005 & na & 3 & na & na \\
Viana do Castelo & Open shore & $\mathbf{0 . 0 0 3}$ & $\mathbf{- 0 . 0 0 3}$ & 0.003 & 10 & 388 & 1.01 \\
Lima River & Estuary & $\mathbf{0 . 0 1 9}$ & $\mathbf{- 0 . 0 2}$ & 0.02 & 3 & 35.8 & 0.96 \\
Tagus River & Estuary & 0.001 & -0.002 & na & 5 & na & na \\
\hline
\end{tabular}

\section{Kinship structure}

In the Tagus River population $(1 \times 1 \mathrm{~m}), 37$ random recruits were sampled within the adult population, for which the putative parents in the same area included 22 female and 17 male thalli. Of the 1849 dyads considered in the Tagus River recruits, we obtained 70 half-sib dyads (3.8\%) and no full-sib relationships. Twelve mother-offspring dyads were found, as 3 of the sampled female thalli were the probable mothers of 12 recruits. Three father-offspring dyads were detected and one male thallus was the probable father of the 3 offspring.

In Viana do Castelo $(5 \times 5 \mathrm{~m}), 45$ random recruits were analyzed, and the putative parents sampled from the adult population included 112 females and 100 males. Of the 2025 recruit dyads considered, 8 full-sib $(0.4 \%)$ and $110(5.4 \%)$ half-sib dyads were detected. Eighteen mother-offspring dyads were detected, as 5 of the sampled females were identified as the probable mothers of 18 recruits. Nine father-offspring dyads were detected, in which 3 sampled males were the probable fathers of 9 recruits. Only 5 recruits were detected as offspring of both sampled males and females.

\section{DISCUSSION}

The fine spatial resolution of this study $(<1 \mathrm{~cm}$ to $15 \mathrm{~m}$ ) revealed a lack of SGS for 3 of the 5 Fucus vesiculosus populations studied, 1 estuary (Tagus River) and 2 open coast (Roscoff and Brest), contradicting our hypothesis of SGS at very small scales, and indicating that gene flow at small scales within populations is generally unrestricted. The remaining 2 populations, an estuary (Lima River) and an open coast (Viana do Castelo), revealed weak but signifi- cant SGS patterns. These results suggest restriction to gene flow at a very small scale for some populations independently of the habitat being open shore or estuarine.

SGS could be occurring at a spatial scale even smaller than the scale analysed in the present study, as was found to be the case in other studies (see Krueger-Hadfield et al. 2013). The identification of more putative mothers than fathers occurring near the sampled recruits indicates that male gamete dispersal mediates gene flow at broader distances and could thus be obscuring a much more restricted female gamete dispersal (as shown by Serrão et al. 1997). An alternative hypothesis is the occurrence of a sampling bias towards females (difference in size or longevity). However, this last hypothesis seems unlikely since sampling was random and no female bias was found in natural populations (Engel et al. 2005). Still, most of the parents of the recruits could not be found among the adults sampled nearby, again supporting unrestricted gene flow at small scales.

\section{Inbreeding depression}

Our results support the hypothesis of the important role of inbreeding depression in shaping the genetic structure of $F$. vesiculosus. In the populations where recruits were sampled (Viana do Castelo and Tagus River), we found highly significant heterozygote deficiencies in the 'younger' individuals (recruits) but not in the adults. The decrease in heterozygote deficiency with aging has been reported in various plant species (e.g. Hossaert-McKey et al. 1996, Jacquemyn et al. 2006) and explained by selective effect involving heterozygote advantage or inbreeding depression. In many species, depending on the mechanism behind the increase in homozygous loci in inbred progeny (overdominance or partial dominance; Charlesworth \& Charlesworth 1987), fitness reduction may occur in the early life stages due to highly deleterious alleles, or at later stages in the life cycle, if less deleterious alleles are allowed to accumulate (Lande \& Schemske 1985, Barrett \& Harder 1996). In F. vesiculosus, the difference in inbreeding coefficients of the reproductive adults in relation to their recruits suggests reduced fitness of inbred individuals.

Negative effects of inbreeding on reproductive traits and offspring establishment have been exten- 
sively studied and documented in several outcrossing plant (e.g. Richards 2000, Teixeira et al. 2009) and animal species (e.g. Keller \& Waller 2002). In giant kelp, weaker observed SGS than expected could only be achieved in simulations when high mortality was associated with inbreeding depression (Johansson et al. 2013). Further studies on fitness traits (early and late stages) are needed to ascertain inbreeding depression and its mechanisms in $F$. vesiculosus. In this species, neighbours are competitively harmful, since laboratory experiments revealed a depressed growth of germlings under higher density conditions and in situ experiments showed higher recruitment after canopy thinning (Creed et al. 1996). Competition experiments using different levels of inbred individuals might further elucidate the mechanisms behind our results.

Furthermore, the existence of a bank of microscopic juveniles, resembling a seed bank in land plants, has been reported for this species, where potential preexisting recruits only develop when there is a thinning of the populations' canopy, creating an opportunity for growth (Creed et al. 1996). A higher $F_{\text {IS }}$ has been found for the seed bank in relation to the adult population in several plant species (McCue \& Holtsford 1998 and references therein). Three hypotheses were proposed for the high $F_{\text {IS }}$ levels found in Fucus: (1) higher inbreeding in previous years; (2) temporal Walhund effect (see below), if the generations that contribute to the seed bank have different allelic frequencies; (3) inbreeding depression, through lower survival or germination of inbred individuals (Tonsor et al. 1993).

\section{Genetic diversity}

The decreasing genetic diversity of $F$. vesiculosus from northern France towards the south is in accordance with biogeographic patterns displaying loss of genetic diversity of southern edge populations, possibly due to smaller population sizes in increasingly unfavourable habitats associated with ongoing climatic changes (Nicastro et al. 2013, Assis et al. 2014).

The highly significant heterozygote deficiencies found for all populations except Tagus River are within the ranges previously found for this species (e.g. Engel et al. 2005, Perrin et al. 2007, Tatarenkov et al. 2007, Nicastro et al. 2013), in contrast with Muhlin et al. (2008), who found little departure from random mating expectations. These heterozygote deficiencies may be caused by biparental inbreeding and would suggest restricted gene flow, with most fertilizations occurring between closely related individuals. However, heterozygote deficiencies could have alternative explanations: null alleles or Wahlund effect. The occurrence of null alleles is not the best explanation for our results. Although our loci could be affected, as assessed by the null allele frequencies, these exhibit mainly low frequencies ( $p<0.2$, except for 2 populations), and the use of 'corrected' genotypes, taking into consideration the null alleles, did not change the overall heterozygote deficiency results. Accordingly, highly significant inbreeding coefficients have been found for many populations of $F$. vesiculosus and other Fucus species using different microsatellite markers (Coyer et al. 2003, 2011, Coleman \& Brawley 2005a,b, Engel et al. 2005, Perrin et al. 2007, Tatarenkov et al. 2007, Billard et al. 2010, Nicastro et al. 2013), suggesting that high inbreeding coefficients are the rule in these species. Other explanations could account for high values of $F_{\text {IS }}$, such as the occurrence of temporal or spatial structure. A Wahlund effect can occur when we sample what seems to be one population, but in fact it contains more than one genetically differentiated population. This effect can be spatial and/or temporal. In our study, no spatial substructuring was found within populations (except in Viana do Castelo); however, a species delineation effect could possibly arise if there were hybrid genotypes within populations. Hybrids have been reported in F. vesiculosus populations and especially in Viana do Castelo and Roscoff, where a vertical zonation of several species of Fucus occurs (Zardi et al. 2011). A temporal Wahlund effect has been evoked in previous studies (Coyer et al. 2003, Engel et al. 2005), where the possibility of an age-structured population, with high variance in individual reproductive success between generations, would lead to distinct cohorts being genetically differentiated and/or that these differentiated groups of individuals would reproduce at different times, maintaining the existence of the temporal populations. We did not find significant differences between size classes in the Viana do Castelo population, as measured by $F_{\mathrm{ST}}$ (data not shown), to support a temporal Wahlund effect. The existence of a pool of microscopic juveniles may act as a genetic reservoir, increasing the effective population size $\left(N_{\mathrm{e}}\right)$ and buffering populations from genetic diversity loss (McCue \& Holtsford 1998).

\section{Spatial autocorrelation and kinship}

The absence or low levels of small-scale genetic structure within populations suggests that at short 
scales F. vesiculosus does not form genetic neighbourhoods imposed by restricted gene flow. Suprisingly only 2 of the 4 populations characterised by significant $F_{\text {IS }}$ values showed significant SGS. However, the sampling design used in this study was random, and even though the distance between individuals sampled covered a wide range $(<1 \mathrm{~cm}$ to $15 \mathrm{~m})$, we cannot discard the existence of microgeographic adaptation (Krueger-Hadfield et al. 2013, Richardson et al. 2014). Further studies with smaller interindividual distances should be designed to specifically address microgeographic processes (e.g. siblings growing attached together or attached to the maternal holdfast; Malm \& Kautsky 2004).

The general lack of SGS found in this study is further strengthened by our kinship analysis, where very few (or none) full- and half-sibships were found at spatial scales ranging from 1 to $75 \mathrm{~m}^{2}$. And although recruits were sampled amidst the populations and in most cases under the sampled adult individuals, very few female and male parents were identified (Fig. S1 in the Supplement). Surprisingly, these results seem to indicate that the vast majority of parents of the recruits sampled originated from outside the population while high levels of inbreeding $\left(F_{\mathrm{IS}}\right.$, Tables 1 \& 2) suggest dense recruitment of related individuals.

Here we were able to analyse the possible effect of cohorts on SGS, and only marginally significant SGS was found for one size class. Thus, if size is a good proxy for age, then this may be indicative that reproduction between related cohorts is not different from that expected at random. In this case it is expected that size is a good proxy for age because this is a stable population that we have been following for the last decade, and no demographic perturbations were observed such as large grazing events or physical stress. Furthermore, old individuals with shorter than expected length (e.g. due to physical stress or grazing) typically have distinct holdfasts (larger and darker), and our samples did not include such morphologies.

A hypothesis of temporal Wahlund effect where only some individuals were in reproductive synchrony to originate the sampled recruits seems unlikely; we would have to have sampled by chance only adults that did not spawn successfully in previous reproductive seasons. However, if a large bank of microscopic forms exists and if these juveniles can be maintained in a latent state for long periods of time, this could lead to populations composed of a mosaic of individuals originating from very different reproductive episodes and therefore possibly different genetic compositions (McCauley, 2014). Further studies are needed to elucidate the hypothetical role of microscopic juveniles in shaping the genetic structure of populations.

Finally, we cannot overlook the hypothesis that failure to detect SGS can simply derive from nonequilibrium conditions within the populations. Simulation models suggest that many generations may be needed for SGS to arise and stabilize (Sokal \& Wartenberg 1983, Hossaert-McKey et al. 1996).

\section{Dispersal in external fertilizers}

In sessile external fertilizer species, the release of gametes into the water column can potentially lead to high variability in reproductive success via gamete dilution. Restricting gamete release to synchronous calm periods maximizes reproductive success, but it is expected to result in very strong SGS. However, the majority of broadcast-spawning species exhibit little or no small-scale genetic structure relative to their ecologically equivalent brooders (Bradbury et al. 2008). In F. vesiculosus, although isolation by distance has been reported at larger scales (e.g. Tatarenkov et al. 2007), our results do not confirm the generality of the hypothesis of genetic spatial autocorrelation within very small scales in open coast and estuarine habitats.

In $F$. vesiculosus, the very limited egg dispersal and the calm hydrodynamic conditions during gamete release were expected to originate genetic structure (Serrão et al. 1996, Berndt et al. 2002, Monteiro et al. 2012), but gene flow could still be mediated by other means of dispersal. The eggs of $F$. vesiculosus are negatively buoyant, only attach to the substrate after fertilization and can be viable for several days (Muhlin et al. 2008). Fertilized eggs, although having no planktonic phase, can take 7 to $8 \mathrm{~h}$ to adhere firmly at the temperatures found on these shores (Ladah et al. 2003). During the short interval in which the fertilized eggs are settling through the water column, like planktonic organisms, they are under the influence of hydrodynamic forces described by a low Reynolds number $(\operatorname{Re}<1)$, where viscous forces dominate (Denny 1993). However, while attaching to the substrate, the relative water velocity experienced by the propagules instantly increases in magnitude, leading to higher Re and therefore a turbulent regime with highly variable instantaneous velocities, even when the average velocity of the bulk water motion is constant (Crimaldi et al. 2002). 
Sperm viability, in contrast with that of eggs, lasts only for a few hours (Muhlin et al. 2008). Long-term dispersal is therefore not possible, and it would not be expected to be useful since rapid dilution of sperm, especially under high turbulence, leads to a low probability of fertilization more than a few meters from the sperm source (see review in Levitan \& Petersen 1995). However some strategies may enhance fertilization and counteract the effects of dilution, allowing some benefit from high turbulence in dispersal, particularly the release of mucilage together with the sperm, that may retain gametes together and delay sperm activation in the water column (see review by Serrão \& Havenhand 2009). In red algae sperm are non-motile, but females in tide pools can be successfully fertilized by external males, although the vast majority of fertilizations occur by spatially close males (Engel et al. 1999).

Dispersal via drifting reproductive thalli is also a possibility, as has been found for other brown algae (Lu \& Williams 1994, McKenzie \& Bellgrove 2008). Indeed, this strategy has been suggested to occur for F. vesiculosus, as a hypothesis for the lack of SGS, high genetic diversity and low population genetic differentiation found for some North American populations (Muhlin et al. 2008). However, unlike Halidrys dioica, which produces detaching reproductive fronds as part of their life-cycle (Lu \& Williams 1994), in F. vesiculosus a reproductive thallus has to be broken, by storms or waves, and to our knowledge floating fronds of $F$. vesiculosus occur but not in high densities as found in other brown algae (McKenzie \& Bellgrove 2008). Perhaps this strategy has a higher contribution to long-distance dispersal where a low number of migrants is sufficient to maintain gene flow between populations. Further studies should address the density, frequency and viability of drifting $F$. vesiculosus fronds to address the importance of this type of dispersal.

Dispersal could be further affected by other abiotic factors, particularly in the case of intertidal species, by currents associated to the tidal cycles. However, gametes in $F$. vesiculosus are released during the calm intervals of the tidal cycle, slack high tide or low tide (Berndt et al. 2002, Monteiro et al. 2012).

In this study, we revealed a predominant lack of SGS within populations at small spatial scales, with most matings probably originating from individuals outside (spatially or temporally) the populations. Such high gene flow might be an advantage when faced with habitat alterations, allowing maintenance of local high genetic diversity. However, our study also indicated the important role of inbreeding de- pression in the genetic structure of $F$. vesiculosus populations. This process might reduce overall fitness of the individuals within the very small southernmost populations that have been suffering extensive genetic erosion in comparison with areas further north (Nicastro et al. 2013, Assis et al. 2014).

Acknowledgements. This work was financed by FCT (Fundação para a Ciência e Tecnologia), through projects PTDC/ MAR/104477/2008, EXCL/AAG-GLO/0661/2012, UID/Multi/ 04326/2013 and postdoctoral grant SFRH/BPD/39097/2007 (to S.T.). The authors thank T. Pereira, C. Paulino and C. Monteiro for all sampling assistance provided.

\section{LITERATURE CITED}

Alberto F, Gouveia L, Arnaud-Haond S, Pérez-Lloréns JL, Duarte CM, Serrão EA (2005) Within-population spatial genetic structure, neighbourhood size and clonal subrange in the seagrass Cymodocea nodosa. Mol Ecol 14: 2669-2681

Assis J, Serrão EA, Claro B, Perrin C, Pearson GA (2014) Climate-driven range shifts explain the distribution of extant gene pools and predict future loss of unique lineages in a marine brown alga. Mol Ecol 23:2797-2810

> Barner AK, Pfister CA, Wootton JT (2011) The mixed mating system of the sea palm kelp Postelsia palmaeformis: few costs to selfing. Proc R Soc B 278:1347-1355

Barrett SCH, Harder LD (1996) Ecology and evolution of plant mating system. Trends Ecol Evol 11:73-79

Belkhir K, Borsa P, Chikhi L, Raufaste N, Bonhomme F (1996) GENETIX 4.05, logiciel sous Windows TM pour la génétique des populations. Laboratoire Génome, Populations, Interactions, CNRS UMR 5000, Université de Montpellier II, Montpellier

Benjamini Y, Hochberg Y (1995) Controlling the false discovery rate: a practical and powerful approach to multiple testing. J R Stat Soc, B 57:289-300

> Berndt M, Callow J, Brawley S (2002) Gamete concentrations and timing and success of fertilization in a rocky shore seaweed. Mar Ecol Prog Ser 226:273-285

Billard E, Serrão EA, Pearson GA, Destombe C, Valero M (2010) Fucus vesiculosus and spiralis species complex: a nested model of local adaptation at the shore level. Mar Ecol Prog Ser 405:163-174

Billingham MR, Simões T, Reusch TBH, Serrão EA (2007) Genetic substructure and intermediate optimal outcrossing distance in the marine angiosperm Zostera marina. Mar Biol 152:793-801

Black WC, Krafsur ES (1985) A FORTRAN program for the calculation and analysis of two-locus linkage disequilibrium coefficients. Theor Appl Genet 70:491-496

Blanquer A, Uriz MJ, Caujapé-Castells J (2009) Small-scale spatial genetic structure in Scopalina lophyropoda, an encrusting sponge with philopatric larval dispersal and frequent fission and fusion events. Mar Ecol Prog Ser 380:95-102

Bradbury IR, Laurel B, Snelgrove PVR, Bentzen P, Campana SE (2008) Global patterns in marine dispersal estimates: the influence of geography, taxonomic category and life history. Proc R Soc B 275:1803-1809 
Calderón I, Ortega N, Duran S, Becerro M, Pascual M, Turon $\mathrm{X}$ (2007) Finding the relevant scale: clonality and genetic structure in a marine invertebrate (Crambe crambe, Porifera). Mol Ecol 16:1799-1810

Chapman ARO (1995) Functional ecology of fucoid algae; twenty-three years of progress. Phycologia 34:1-32

Charlesworth D, Charlesworth B (1987) Inbreeding depression and its evolutionary consequences. Annu Rev Ecol Syst 18:237-268

> Coleman MA, Brawley SH (2005a) Spatial and temporal variability in dispersal and population genetic structure of a rockpool alga. Mar Ecol Prog Ser 300:63-77

> Coleman MA, Brawley SH (2005b) Are life history characteristics good predictors of genetic diversity and structure? A case study of the interetidal alga Fucus spiralis (Heterokontophyta: Phaeophyceae). J Phycol 41:753-762

> Coyer JA, Peters AF, Stam WT, Olsen JL (2003) Post-ice age recolonization and differentiation of Fucus serratus L. (Phaeophyceae; Fucaceae) populations in Northern Europe. Mol Ecol 12:1817-1829

Coyer JA, Hoarau G, Beszerti B, Pearson GA, Olsen JL (2009) Expressed sequence tag derived polymorphic SSR markers for Fucus serratus and amplification in other species of Fucus. Mol Ecol Resour 9:168-170

Coyer JA, Hoarau G, Costa JF, Hogerdijk B and others (2011) Evolution and diversification within the intertidal brown macroalgae Fucus spiralis/F. vesiculosus species complex in the North Atlantic. Mol Phylogenet Evol 58: 283-296

Creed JC, Norton TA, Kain JM (1996) Are neighbours harmful or helpful in Fucus vesiculosus populations? Mar Ecol Prog Ser 133:191-201

> Crimaldi JP, Thompson JK, Rosman JH, Lowe RJ, Koseff JR (2002) Hydrodynamics of larval settlement: the influence of turbulent stress events at potential recruitment sites. Limnol Oceanogr 47:1137-1151

> Delph LF (2004) Testing for sex differences in biparental inbreeding and its consequences in a gynodioecious species. Am J Bot 91:45-51

Denny MW (1993) Air and water: the biology and physics of life's media. Princeton University Press, Princeton, NJ

> Dudgeon S, Kubler JE, Wright WA, Vadas RL, Petraitis PS (2001) Natural variability in zygote dispersal of Ascophyllum nodosum at small spatial scales. Funct Ecol 15: 595-604

> Engel CR, Wattier R, Destombe C, Valero M (1999) Performance of non-motile male gametes in the sea: analysis of paternity and fertilization success in a natural population of a red seaweed, Gracilaria gracilis. Proc R Soc B 266: 1879-1886

Engel CR, Brawley SH, Edwards KJ, Serrão EA (2003) Isolation and cross-species amplification of microsatellite loci from the fucoid seaweeds Fucus vesiculosus, F. serratus and Ascophyllum nodosum (Heterokontophyta, Fucaceae). Mol Ecol Notes 3:180-182

> Engel CR, Destombe C, Valero M (2004) Mating system and gene flow in the red seaweed Gracilaria gracilis: effect of haploid-diploid life history and intertidal rocky shore landscape on fine-scale genetic structure. Heredity 92: 289-298

> Engel CR, Daguin C, Serrão EA (2005) Genetic entities and mating system in hermaphroditic Fucus spiralis and its close dioecious relative F. vesiculosus (Fucaceae, Phaeophyceae). Mol Ecol 14:2033-2046

> Hardy OJ, Vekemans X (2002) SPAGEDI: a versatile com- puter program to analyse spatial genetic structure at the individual or population levels. Mol Ecol Notes 2: $618-620$

Hossaert-McKey M, Valero M, Magda D, Jarry M, Cuguen J, Vernet P (1996) The evolving genetic history of a population of Lathyrus sylvestris: evidence from temporal and spatial genetic structure. Evolution 50:1808-1821

Jacquemyn H, Brys R, Vandepitte K, Honnay O, RoldánRuiz I (2006) Fine-scale genetic structure of life history stages in the food-deceptive orchid Orchis purpurea. Mol Ecol 15:2801-2808

> Johansson ML, Raimondi PT, Reed DC, Coelho NC, Serrão EA, Alberto FA (2013) Looking into the black box: simulating the role of self-fertilization and mortality in the genetic structure of Macrocystis pyrifera. Mol Ecol 22: 4842-4854

> Jones OR, Wang J (2010) COLONY: a program for parentage and sibship inference from multilocus genotype data. Mol Ecol Resour 10:551-555

Kalinowski ST, Taper ML (2006) Maximum likelihood estimation of the frequency of null alleles at microsatellite loci. Conserv Genet 7:991-995

Keller L, Waller D (2002) Inbreeding effects in wild populations. Trends Ecol Evol 17:230-241

Krueger-Hadfield SA, Roze D, Mauger S, Valero M (2013) Intergametophytic selfing and microgeographic genetic structure shape populations of the intertidal red seaweed Chondrus crispus. Mol Ecol 22:3242-3260

Krueger-Hadfield SA, Roze D, Correa JA, Destombe C, Valero M (2015) O father where art thou? Paternity analyses in a natural population of the haploid-diploid seaweed Chondrus crispus. Heredity 114:185-194

Kusumo HT, Pfister CA, Wootton JT (2006) Small-scale genetic structure in the sea palm Postelsia palmaeformis Ruprecht (Phaeophyceae). Mar Biol 149:731-742

- Ladah L, Bermudez R, Pearson G, Serrão E (2003) Fertilization success and recruitment of dioecious and hermaphroditic fucoid seaweeds with contrasting distributions near their southern limit. Mar Ecol Prog Ser 262: 173-183

Lande R, Schemske DW (1985) The evolution of self-fertilization and inbreeding depression in plants. I. Genetic models. Evolution 39:24-40

Ledoux JB, Garrabou J, Bianchimani O, Drap P, Féral JP, Aurelle D (2010) Fine-scale genetic structure and inferences on population biology in the threatened Mediterranean red coral, Corallium rubrum. Mol Ecol 19: 4204-4216

Levitan DR, Petersen C (1995) Sperm limitation in the sea. Trends Ecol Evol 10:228-231

Loiselle BA, Sork VL, Nason J, Graham C (1995) Spatial genetic structure of a tropical understory shrub, Psychotria officinalis (Rubiaceae). Am J Bot 82:1420-1425

Lu TT, Williams SL (1994) Genetic diversity and structure in Pelvetia fastigiata (Phaeophyta: Fucales): Does a small effective neighborhood size explain fine-scale genetic structure? Mar Biol 121:363-371

Malm T, Kautsky L (2004) Are bladderwrack (Fucus vesiculosus L.) holdfasts that support several fronds composed of one or serveral genetic individuals? Aquat Bot 80: 221-226

McCauley D (2014) What is the influence of the seed bank on the persistence and genetic structure of plant populations that experience a high level of disturbance? New Phytol 202:734-735 
McCue KA, Holtsford TP (1998) Seed bank influences on genetic diversity in the rare annual Clarkia springvillensis (Onagraceae). Am J Bot 85:30-36

McKenzie P, Bellgrove A (2006) No outbreeding depression at a regional scale for a habitat-forming intertidal alga with limited dispersal. Mar Freshw Res 57:655-663

McKenzie P, Bellgrove A (2008) Dispersal of Hormosira banksii (Phaeophyceae) via detached fragments: reproductive viability and longevity. J Phycol 44:1108-1115

Monteiro CA, Serrão EA, Pearson GA (2012) Prezygotic barriers to hybridization in marine broadcast spawners: reproductive timing and mating system variation. PLoS ONE 7:e35978

Muhlin JF, Engel CR, Stessel R, Weatherbee RA, Brawley $\mathrm{SH}$ (2008) The influence of coastal topography, circulation patterns, and rafting in structuring populations of an intertidal alga. Mol Ecol 17:1198-1210

> Nicastro KR, Zardi GI, Teixeira S, Neiva J, Serrão EA, Pearson GA (2013) Shift happens: trailing edge contraction associated with recent warming trends threatens a distinct genetic lineage in the marine macroalga Fucus vesiculosus. BMC Biol 11:6

> Pearson GA, Serrão EA (2006) Revisiting synchronous gamete release by fucoid algae in the intertidal zone: fertilization success and beyond? Integr Comp Biol 46: 587-597

> Perrin C, Daguin C, Van de Vliet M, Engel CR, Pearson GA, Serrão EA (2007) Implications of mating system for genetic diversity of sister algal species: Fucus spiralis and Fucus vesiculosus (Heterokontophyta, Phaeophyceae). Eur J Phycol 42:219-230

Raimondi PT, Reed DC, Gaylord B, Washburn L (2004) Effects of self-fertilization in the giant kelp, Macrocystis pyrifera. Ecology 85:3267-3276

Richards CM (2000) Inbreeding depression and genetic rescue in a plant metapopulation. Am Nat 155:383-394

Richardson JL, Urban MC (2013) Strong selection barriers explain microgeographic adaptation in wild salamander populations. Evolution 67:1729-1740

Richardson JL, Urban MC, Bolnick DI, Skelly DK (2014) Microgeographic adaptation and the spatial scale of evolution. Trends Ecol Evol 29:165-176

Richerd S, Destombe C, Cuguen J, Valero M (1993) Variation of reproductive success in a haplo-diploid red alga, Gracilaria verrucosa: effects of parental identities and crossing distance. Am J Bot 80:1379-1391

Ronce O (2007) How does it feel like being a rolling stone? Ten questions about dispersal evolution. Annu Rev Ecol Evol Syst 38:231-253

Rousset (2002) Genetic differentiation between individuals. J Evol Biol 13:58-62

Serrão EA, Havenhand J (2009) Fertilization strategies. In: Wahl M (ed) Marine hard bottom communities. Springer-
Verlag, Berlin, p 149-164

Serrão EA, Pearson G, Kautsky L, Brawley SH (1996) Successful external fertilization in turbulent environments. Proc Natl Acad Sci USA 93:5286-5290

Serrão EA, Kautsky L, Lifvergren T, Brawley SH (1997) Gamete dispersal and pre-recruitment mortality in Baltic Fucus vesiculosus. Phycologia 36:101-102

Sletvold N, Mousset M, Hagenblad J, Hansson B, Ågren J (2013) Strong inbreeding depression in two Scandinavian populations of the self-incompatible perennial herb Arabidopsis lyrata. Evolution, doi:10.1111/evo.12174

Sokal RR, Wartenberg DE (1983) A test of spatial autocorrelation analysis using an isolation-by-distance model. Genetics 105:219-237

Storey JD (2002) A direct approach to false discovery rates. J R Stat Soc, B 64:479-498

> Tatarenkov A, Jönsson RB, Kautsky L, Johannesson K (2007) Genetic structure in populations of Fucus vesiculosus (Phaeophyceae) over spatial scales from $10 \mathrm{~m}$ to $800 \mathrm{~km}$. J Phycol 43:675-685

Teixeira S, Foerster K, Bernasconi G (2009) Evidence for inbreeding depression and post-pollination selection against inbreeding in the dioecious plant Silene latifolia. Heredity 102:101-112

Tonsor SJ, Kalisz S, Fisher J, Holtsford TP (1993) A life history based study of population genetic structure: seed bank to adults in Plantago lanceolata. Evolution 47: 833-843

van Oosterhout C, Hutchinson WF, Wills DPM, Shipley P (2004) MICROCHECKER: software for identifying and correcting genotyping errors in microsatellite data. Mol Ecol Notes 4:535-538

> Vekemans X, Hardy OJ (2004) New insights from fine-scale spatial genetic structure analyses in plant populations. Mol Ecol 13:921-935

- Wallace AL, Klein AS (2004) Determining the affinities of salt marsh fucoids using microsatellite markers: evidence of hybridization and introgression between two species of Fucus (Phaeophyta) in a Maine estuary. J Phycol 40: 1013-1027

> Wang J (2004) Sibship reconstruction from genetic data with typing errors. Genetics 166:1963-1979

- Wang J, Santure A (2009) Parentage and sibship inference from multilocus genotype data under polygamy. Genetics 181:1579-1594

- Waser NM, Price MV (1994) Crossing-distance effects in Delphinium nelsonii: outbreeding and inbreeding depression in progeny fitness. Evolution 48:842-852

Wright S (1943) Isolation by distance. Genetics 28:114-138

Zardi GI, Nicastro KR, Cánovas F, Costa JF, Serrão EA, Pearson GA (2011) Adaptive traits are maintained on steep selective gradients despite gene flow and hybridization in the intertidal zone. PLoS ONE 6:e19402

Submitted: February 23, 2015; Accepted: January 12, 2016 Proofs received from author(s): February 8, 2016
Editorial responsibility: Karen Miller,

Hobart, Tasmania, Australia 